RESEARCH ARTICLE

\title{
Impact of Taekwondo Practice on Self-Esteem in adolescents with Attention Deficit Hyperactivity Disorder
}

\author{
Abdelmottaleb Kadri ${ }^{{ }^{*}}$ and Fairouz Azaiez ${ }^{2}$ \\ ${ }^{1}$ Higher Institute of Sport and Physical Education of Ksar Said University of La Manouba, Manouba 2010, Tunisia \\ ${ }^{2}$ Higher Institute of Sport and Physical Education of Sfax, University of Sfax, Sfax 3000, Tunisia
}

*Corresponding author: Abdelmottaleb Kadri, Higher Institute of Sport and Physical Education of Ksar Said University of La Manouba, Manouba 2010, Tunisia, Tel: 98442970,E-mail: abdelmottalebkadri@gmail.com

Citation: Abdelmottaleb Kadri, Fairouz Azaiez (2021) Impact of Taekwondo Practice on Self-Esteem in adolescents with Attention Deficit Hyperactivity Disorder. SAJ Case Report 8: 109. doi: 10.18875/2375-7043.8.105

\begin{abstract}
Attention Deficit Hyperactivity Disorder ADHD is defined as a persistent mode of inattention, hyperactivity and impulsivity that interferes with adolescent functional processing. The real benefits of Takwondo practice are mental rather than physical. Taekwondo integrates Poomsae to focus, release energy and to achieve the unity of executive function. This study aimed to investigate whether Taekwondo practice improves the self-esteem of adolescents with Attention Deficit Hyperactivity Disorder. Previous research has not examined the potential relationship between physical activity interventions and psychological domains of adolescents with ADHD. The aim of this study was to inquire the impacts of one and a half year Taekwondo (TKD) intervention on cognitive function in adolescents with ADHD. The data obtained on the general self-esteem subscale reveals the presence of significant differences according to the TKD group $(\mathrm{F}=19.4 \pm 2.6, \mathrm{P}<0,001)$ and measurement times $(\mathrm{F}=14.0 \pm 2.2, \mathrm{P}<0.001)$. An interaction effect is also noted $(\mathrm{F}=15.7, \mathrm{P}<0.001)($ Large $\mathrm{ES}=2.53[95 \% \mathrm{CI}$ 2.6 to -2.2$])$. Comparisons between the TKD and control groups at baseline reveal significant differences by Cooper Smith's test SEI. In statistical analysis, we concluded the following results: There is significant increase in Total self-esteem for TKD group $(35.5 \pm 5.1 \mathrm{P}<0,001)(21.2 \pm 3.8 \mathrm{P}<0,001)$. (Large ES $=-5.63$ [95\% CI -5.1 to -3.8$]$ ). Practitioners should implement martial art program in their general plan to favorably influence attention and health.
\end{abstract}

Keywords: ADHD; Self-Esteem; Taekwondo; Martial Art 


\section{Introduction}

ADHD disorder is related to many physical, cognitive, psychological, and social changes. this era of turmoil is usually related to a decrease in self-esteem [1]. Self-esteem may be a general and subjective self-assessment of one's personal worth. This assessment touches on several areas which will vary independently. Some areas of self-worth like physical, athletic and academic esteem are more sensitive to physical and psychological changes in adolescence [2]. consistent with Harter [3], the transition to adolescence is amid a complexification of the composition of self-esteem. With age, psychological functioning sharpens and therefore the comparison with others becomes more and more precise. The repercussions of this process of comparison are often important. Evidence from this research suggests a positive effect of Taekwondo's intervention program on self-esteem in adolescents with ADHD. During this sense, Taekwondo are often seen as a vehicle for developing self-esteem due to its positive effects on psychological state. Recreational and fitness activities are shown to be helpful for various special needs populations [4], Since martial arts practice can have beneficial outcomes, varieties of individuals are looking to the martial arts as a way to treat psychological problems. as an example, [5] found that ladies recovering from psycho-sexual abuse, eating disorders, drug abuse and growing up in dysfunctional families reported that karate training was helpful in their recovery. During a case study, [6] claim that Shotokan Karate helped a client achieve quicker leads to verbal therapy. These mental benefits are achieved partly through hard physical training and partly through the mixing of philosophy into training. Specific philosophies differ greatly from one style to a different, and even from one school to a different, but the essential principles they share are respect for "seniors" (such as instructors and parents), consideration of the youngest and weakest, difficult tasks and, perhaps most significantly, self-integrity and doing what's "right" [7]. These positive effects are documented. "Indoctrinated with the thought of respect," martial arts students tend to become better students in school [8]. Variety of writers views this feature because the key to creating martial arts an efficient means of conveying desirable moral values. for instance, [9] argues that the inclusion of a standard self-defense during a education program in grade school would be beneficial to children, as these arts emphasize physical skills and morality and values. [10] also believe that Taekwondo should be directly integrated into school curricula to market the "cyclical" relationship between Taekwondo and private life, during which students reduce "immature or maladaptive behaviors" to excel in Taekwondo; which helps positively to "develop their human personality", which, in turn, helps them to excel in Taekwondo. Taekwondo programs that recognize and understand the way to effectively teach young adolescents take the very characteristics that are the symptoms of ADHD diagnosis (the symptom drug acts to suppress them) and direct them to the physical and mental training of art. As a combat instructor notes, "Often, an adolescent who" disrupts "a course are often a crucial a part of how you'll change your instructional direction" [11]. For instance, an adolescent with significant needs, like someone with an ADHD problem, sets the bar for a trained martial arts teacher to satisfy for his class as an entire. The training aims to show ADHD behavior from destructive to creative and positive, not by blocking or fighting it, but by accepting it first then making it work for the adolescent [12]. Taekwondo training therefore has the potential to effect this positive transformation on each of the essential triads of ADHD impulsivity, distractibility and hyperactivity symptoms. The physical demands of Taekwondo amiliate the body and lower the impulsive fringe of the hyperactive adolescent. Additionally, exercises learned in Dojang are often practiced reception, where the ADHD teenager can "show" his achievements to oldsters. Taekwondo training also provides teens and fogeys with specific tools (exercises) during which hyperactivity or excess energy are often channeled. If the teenager "bounces on the walls," a parent may encourage him to practice a form, work together on punches, kicks, or blocks, or maybe simply to perform tricks or make sit-ups, sort of techniques and combinations for the exercises and activities taught in each Taekwondo program. This selfdefense is often beneficial for the adolescent with ADHD is meditation or other relaxation techniques. [13] Learning self-control is a crucial principle of the many Taekwondo philosophies and disciplines, and this is often the elemental challenge facing ADHD people. In Taekwondo, adolescents learn to regulate their bodies and control their emotions and reactions. By practicing kicks, punches, blocks and jets (depending on the precise martial art) with partners, they learn to regulate the way they use their hands and feet to avoid hurting one another. They also learn to not get angry and to not anger and revenge [14]. They learn to use their meditation, relaxation and breathing techniques to calm themselves down and obtain right down to earth [15]. All of those benefits also benefit the ADHD teenager within the Taekwondo program. All of those skills are often transferred to the regular classroom [16]. Indeed, if a student has an efficient and sincere instructor, such a transfer is inevitable [17]. However, educators and fogeys got to make a concentrated effort to make sure that adolescents with ADHD perceive the links between what they learn in Taekwondo Dojang and the way they will apply it to their surroundings. However, unless adolescents see the link between Taekwondo and more formal 
educational activities, they're going to unlikely let Taekwondo have a positive effect on their school work [18]. the last word reason why Taekwondo are often beneficial for teens with ADHD is their overt goal of turning the practitioner into a far better person. The central struggle for the martial artist, young or old, is internal; it's said that "the hardest enemy is yourself" [19]. The practice of Taekwondo gives young practitioner's tools with which they can turn into something positive. Adolescents with ADHD can be encouraged to manage their academic challenges with the same self-control, perseverance, and overall attitude with which they approach Taekwondo training. Some benefits can easily and easily be removed, for example the benefits of better concentration and better physical well-being. Others, such as the ability to cope with difficult tasks one step at a time, may require parents and educators to make an explicit connection to the adolescent [20]. There are, of course, disadvantages and difficulties in using a regular and sustained training program as an ADHD control tool. As it is not the martial arts activity that magically transforms the teenager, but rather the instructor who gives the teenager the tools to treat ADHD symptoms outside of Taekwondo classes, treat ADHD with Taekwondo can take longer and, sometimes, more expensive than automatically treating the disorder with available medications. This requires considerable commitment and work on the part of the parents and the active participation of the adolescent in the process. In addition, it requires a good instructor and Taekwondo program. It may be worth pointing out that, in order to evaluate their effectiveness in treating the symptoms of ADHD, the practice of Taekwondo has' effects and potential benefits of training for the adolescent with ADHD will be unlocked only if the instructor teaches Taekwondo knowing that the lesson is not only physical [21], that is, the benefits do not come only from exercise, but from the way in which Exercise is taught and philosophy that underlies teaching. More studies need to be conducted in this area in order to further explain the relationship between martial arts training and psychological factors such as self-esteem.

\section{Experimental Section}

\section{Physical characteristics of the subjects at baseline}

Data on the socio-demographic profile of participants are presented in Table 1. The groups are equivalent in age. The distribution by sex is also proportionally respected. The composition of the groups does not respect the matching according to the field of study. The recruitment of the control subjects was carried out accordingly.

\section{Population selection: inclusion/exclusion criteria}

Forty youthful cases with ADHD (36 males and 4 females) were signed. They were desultorily allocated to a TKD practice group (TKDG, $\mathrm{n}=20$, age $=14.5 \pm 3.5$ vintages weight, $=46.5 \pm 11.8$, size $=154.3 \pm 7.6)$ or an impact group $(C G, \mathrm{n}=20$, age $=14.2 \pm 3$ vintages, weight $=46.9 \pm 11.5$ size $=154.1 \pm 7.7$,) with none physical training. To be eligible to share within the study, practionners were warranted to satisfy the posterior criteria (a) no consumption of any supplements or specifics; (b) no history of use of specifics that would alter the hypothalamic-pituitary-gonadal (HPG HPG) axis, like anabolic steroids; (c) no history of inveterate trouble, bronchospasm or atopy; (d) regular eating patterns; (e) no respiratory tract infection during the prior month; (f) abstinence from violent exercise within the $48 \mathrm{~h}$ before testing and (g) not being color visionless or vision- vitiated. Immigrant institutional ethical OK was supplied for this study, which was conducted in tune with the 1964 Helsinki protestation and its posterior emendations. Written warrant was won from the sharers and their parents following description of all experimental details, before experimental data collection. The study was conducted from September 2015 to January 2017. practitioners visited the laboratory on three separate occasions at an lasting time of day (2 2p.m.), it separated by 1 week. The practitioners were familiarized with the testing procedures at visit 1 and, subsequently, were desultorily allocated to at least one of the 2 conditions (TKDG TKDG or CG). The primary visit sorted of the gathering of anthropometric data. Either, players were familiarized with the IPAT scale of rage. During the former visit, players were asked to perform the above mentioned tests, before completing one among two conditions. A rest interval of a minimum of 5-min was handed between tests. An former tests were also performed after each condition. The practitioners of the TKD group performed varicolored specific TKD tacks and poomsaes. The practitioners of the control group performed other exertion resembling physical educational. Practitioners were informed to avoid cognitive exercise, caffeine, and alcohol $48 \mathrm{~h}$ before each laboratory visit. Food and fluid input was registered $48 \mathrm{~h}$ before the primary study visit, and subjects were asked to avoid resembling input $3 \mathrm{~h}$ before the former visit. 


\section{Instruments}

\section{Cooper Smith's self-esteem (SEI)}

His test assesses self-esteem, which is defined because the expression of self-endorsement or disapproval [22]. Belief in personal success, involvement and well-being at work are partly associated with self-esteem. Self-esteem is taken into account across 4 subscales: general, family, social and academic self-esteem. The tool consists of 58 sentences expressing a possible way of thinking or reacting for every sentence, the topic must tick the acceptable box: "looks like me" or "does not appear as if me"; 8 of the 58 items don't serve to assess self-esteem, but incorporate a ladder of lies. Both versions (School and Adult) have good Loyalty Indices.

\section{Taekwondo Intervention}

For a year and a half TKD group practiced specific exercises for 50-min twice weekly. Training sessions happened between 3 and $7 \mathrm{pm}$. The intervention happened during a private martial arts Dojang (researcher).The Taekwondo intervention program consisted of the event technical aspect (e.g. blocking, punching and kicking) of the game and poomsae (forms) for 30-min. Before each training

\begin{tabular}{|l|l|l|l|l|}
\hline Program & \multicolumn{1}{|c|}{ Static activity } & Dynamic activity & $\begin{array}{l}\text { Psychological and } \\
\text { Cognitive functions } \\
\text { targeted }\end{array}$ & $\begin{array}{l}\text { Time } \\
(\mathbf{m i n})\end{array}$ \\
\hline Echauffement & \multicolumn{2}{|l|}{$\begin{array}{l}\text { Stretching, jogging and strengthening (sit-up } \\
\text { and push-up) }\end{array}$} & \multicolumn{2}{|l|}{} \\
\hline $\begin{array}{l}\text { locks and body } \\
\text { punch }\end{array}$ & $\begin{array}{l}\text { Defense position } \\
\text { Upper }\end{array}$ & Walk forwards / backwards & $\begin{array}{l}\text { Visual selective } \\
\text { attention } \\
\text { Focused attention }\end{array}$ & Five \\
\hline Down & Large position & Wolking back ward/forward & & \\
\hline Inside & & & & \\
\hline Out side & & & & \\
\hline
\end{tabular}

\begin{tabular}{|c|c|c|c|c|}
\hline Kicking & & & & Five \\
\hline $\begin{array}{l}\text { Front Lateral On } \\
\text { the back }\end{array}$ & $\begin{array}{l}\text { Fighting } \\
\text { position }\end{array}$ & Walking forward / backwar & $\begin{array}{l}\text { Visual Sustained } \\
\text { Attention }\end{array}$ & \\
\hline Tour yourself & & Jump & & \\
\hline Side & & & & \\
\hline \multicolumn{4}{|c|}{ Objective of MTP } & \multirow[b]{2}{*}{ Thirty } \\
\hline Poomsae & Mouvement & $\begin{array}{l}\text { Forward / backwardb } \\
\text { Left right } \\
\text { Turn in yourself } \\
\text { Down } \\
\text { To the top } \\
\text { No foot wide / short }\end{array}$ & $\begin{array}{l}\text { Alternation / } \\
\text { attentional } \\
\text { Self Esteem }\end{array}$ & \\
\hline 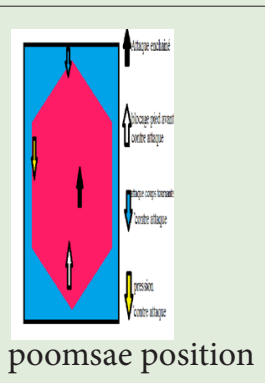 & 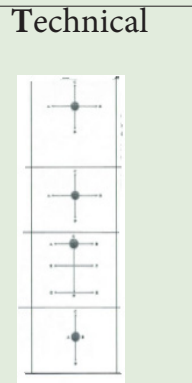 & $\begin{array}{l}\text { Looking forward } \\
\text { Efficiency } \\
\text { Coordination } \\
\text { Attentait } \\
\text { Target } \\
\text { Balanced } \\
\text { Agility } \\
\text { Vigilance } \\
\text { Confirmation }\end{array}$ & $\begin{array}{l}\text { Learning } \\
\text { Auditory work } \\
\text { memory } \\
\text { Verbal working } \\
\text { memory } \\
\text { Visual work } \\
\text { memory } \\
\text { self-confidence }\end{array}$ & \\
\hline & Placement & $\begin{array}{l}\text { Softness } \\
\text { Flexible }\end{array}$ & Self-regulation & \\
\hline Relaxation & & Stretching group game & $\begin{array}{l}\text { Concentration } \\
\text { calm }\end{array}$ & Ten \\
\hline
\end{tabular}

MTP Intervention Program (Movements and Techniques of Poomsaes) 
session, participants completed a 10-min general warm-up and recovery, respectively. Qualified TKD instructors led the TKD intervention. A Taekwondo intervention scheme (see table)

\section{Statistical analysis}

Concerning the statistical analysis, data were visually examined for implicit outliers, before faring with their manipulation. They were represented as group mean values and standard detours (SD SD). Range values were also reported where felicitous. After authenticating data normalcy if with the Shapiro-Wilk test (which which was preferred to other normalcy tests due to the small sample size used in the present exploration), exploratory paired Pupil 's t- test were used to determine genesis between group differences and training goods over time, using Bonferroni correction to guarantee protection against multiple testing. Dependent variables were assayed in separate 2 Groups (TKDG - CG) $\times 2$ (Time pre, post). Either, analysis of dissension (ANOVA) with repeated measures on time was performed. The Mauchly's Sphericity Test was applied in order to control data for the sphericity if, that's to authenticate whether the dissensions of the differences between all possible combinations or couples of groups (or or said otherwise all the possible positions of the independent variable) were equal. In case of sphericity violation, data were corrected using the Conservatory-Geisser correction or the Huynh-Feldt correction, hung on the value of the epsilon. Another in detail, if the epsilon was lesser than 0.75 , the first approach was used, otherwise the second was preferred. Effect sizes (ES) were determined by calculating Cohen's d values with their 95 confidence interval or CI [23]. Cohen's d values were classified as small $(0.00 \leq \mathrm{d} \leq 0.49)$, medium $(0.50$ $\leq \mathrm{d} \leq 0.79$ ), and large goods ( $\mathrm{d} \mathrm{d} \geq 0.80$ ) according to the Cohen's rule of thumb [24]. A significance position of $\mathrm{p} \leq 0.05$ was set for all analyses. All statistical analyses were carried out using the marketable software "Statistical Package for Social Science" for Windows (SPSS Inc., Chicago, IL, USA, and interpretation.16.0).

\begin{tabular}{|c|c|c|c|c|c|c|c|c|c|}
\hline \multirow[t]{2}{*}{ Variables } & \multicolumn{4}{|c|}{ Control Group } & \multicolumn{5}{|c|}{ TKD group } \\
\hline & Pré-test & Postest & \multicolumn{2}{|c|}{ Sig statistical } & Pré-test & Postest & $\begin{array}{l}\text { Sig } \\
\text { statistical }\end{array}$ & $\begin{array}{l}\text { TKD vs. } \\
\text { Control } \\
\text { Group }\end{array}$ & $\begin{array}{l}\text { Global } \\
\text { effect Size }\end{array}$ \\
\hline \multicolumn{10}{|c|}{ Cooper Test } \\
\hline General self esteem & $15.4 \pm 2.3$ & $14.0 \pm 2.2$ & $<0.001$ & \multicolumn{2}{|c|}{$15.3 \pm 2.5$} & $19.4 \pm 2.6$ & $<0.001$ & 0.111 & 2.53 \\
\hline Social self-esteem & $2.7 \pm 1.3$ & $3.6 \pm 1.1$ & $<0.001$ & \multicolumn{2}{|c|}{$2.4 \pm 1$} & $5.5 \pm 1.4$ & $<0.004$ & 0.020 & 2.60 \\
\hline familial self-esteem & $2.9 \pm 0.7$ & $1.9 \pm 0.8$ & $<0.001$ & \multicolumn{2}{|c|}{$2.3 \pm 1$} & $5.4 \pm 1$ & $<0.001$ & 0.075 & 3.11 \\
\hline School self esteem & $3.2 \pm 1.1$ & $1.7 \pm 0.7$ & $<0.001$ & \multicolumn{2}{|c|}{$2.5 \pm 1.1$} & $5.6 \pm 1.1$ & $<0.001$ & 0.003 & 3.5 \\
\hline totals & $24.2 \pm 4.7$ & $21.2 \pm 3.8$ & $<0.001$ & \multicolumn{2}{|c|}{$23.2 \pm 5.6$} & $35.5 \pm 5.1$ & $<0.001$ & 0.074 & -5.63 \\
\hline
\end{tabular}

Mean values and standard deviations (SD) of psychological test (Cooper Smith test) before and after the intervention, their statistical significance and the overall size of their effects (ES)

Table 1: Impact of taekwondo practice (TKD) on the Cooper Smith test between the TKD group and control group

\section{Results}

The results obtained in Coopersmith self-esteem Inventory (SEI) are presented in Table 1. Significant differences are noted in the total measure of self-esteem. The analysis of the results shows a totals variables time effect of measurements in postest $(\mathrm{F}=24.2 \pm 4,7$ $\mathrm{P}<0.001)$ and an interaction effect $(\mathrm{F}=23.2 \pm 5.6, \mathrm{P}<0.001)$. An interaction effect is $(\mathrm{F}=21.3 \pm 5.1, \mathrm{P}<0.001)$. (Large ES $=-5.630[95 \%$ CI -5.1 to -3.8$])$. The analysis of the results obtained on the general self-esteem subscale reveals the presence of significant differences according to the TKD group $(\mathrm{F}=19.4 \pm 2.6, \mathrm{P}<0,001)(\mathrm{F}=14.0 \pm 2.2, \mathrm{P}=0.03)$. An interaction effect is also noted $(\mathrm{F}=15.4 \pm 2.3, \mathrm{P}$ $<0.001$ ) (large ES $=2.53$ [95\% CI 1.2, 6 -2.2]). Differences are also updated at the subscale level of social esteem. A significant effect is observed when comparing the results obtained at different measurement times $(\mathrm{F}=5.5 \pm 1.4, \mathrm{P}<0.004)$. A significant interaction effect is also noted $(\mathrm{F}=3.6 \pm 1.1, \mathrm{P}<0.004)$ (large $\mathrm{ES}=2.60[95 \% \mathrm{CI} 1.4-1.1])$. Similar results are obtained when analyzing data on school esteem. A significant difference is obtained as a function of the measurement times $(\mathrm{F}=5.6 \pm 1.1, \mathrm{P}=0.007)$. ( $\mathrm{F}=1.7 \pm 0.7, \mathrm{P}$ 
$<0.001)$. An effect interaction is also noted $(\mathrm{F}=3.6, \pm 2,3 \mathrm{P}=0.007)$. (Large ES $=3.5$ [95\% CI 1.7-1.1]). The results obtained on the family esteem subscale show significant differences $(\mathrm{F}=5.4 \pm 1 \mathrm{P}=0.001)$. $(\mathrm{F}=1.9 \pm 0.8 \mathrm{P}<0.001)$. An effect interaction is also noted $(\mathrm{F}=3.7 \pm 1,4 \mathrm{P}=0.007)$ (large $\mathrm{ES}=3.11$ [95\% CI 1.9-1.]). In summary, a significant improvement in the variables tasks was observed between pretest and postest in the TKD group. Thus, the Poomsae Training Program processes a significant improvement in Selfesteem among adolescents with ADHD.

\section{Discussion}

The results of this study suggest that Taekwondo practice may improve self-esteem in adolescents with ADHD (Table 1). TKD group improved their self-esteem after the 78-week Taekwondo MTP intervention program, while the control group had a lower selfesteem during the baseline period, which may explain their apparent lack of improvement. This result is consistent with previous findings that martial arts practice improves the exercises personal effectiveness [25]. They found that a 15-week tai chi program had a significant effect on the self-esteem among university students. indicating that participants consider themselves to be better able to control their thoughtful way at the end of the intervention only at the beginning. Psychologically very similar to our Taekwondo program for 78 weeks also had a positive impact on the self-efficacy of exercise among adolescents with ADHD [26]. The results of this study also support previous studies that have shown that martial arts programs improve physical self-esteem [27]. For example, practicing tai chi for six months improved self-esteem. They used the SEI to measure their self-esteem and found improvement in all subdomains [28]. We found an improvement in all SEI subdomains in adolescents with ADHD, which resulted in a higher self-esteem score for the TKD group. Our findings propose a hierarchical structure of SEI subdomains, which appears to improve self-esteem through our Taekwondo MTP intervention program. In contrast to their study, in our study, we followed a multiple basic approach rather than designing their randomized controlled trials study. A multiple basic approach has been described as a viable alternative to randomized controlled trials that use smaller and still statistically rigorous samples [29]. When collecting baseline data, after the Taekwondo MTP intervention program, the TKD group appears to have developed social and family self-esteem(Table 1). Conversely, intellectual ability and morality were initially different for all participants, but the TKD group showed a complete improvement after Taekwondo's MTP intervention program. Social relationships were previously identified as one of the main reasons for practicing martial arts and it has been argued that martial arts practice enhances social acceptance [30]. In a previous study, it was found that social self-esteem was improved through Taekwondo training in adolescents with ADHD [31]. Although a comparative study was used in our study, in which participants were trained in two groups $(n=40)$ for 78 weeks, it appears that the period was sufficient to improve their self-esteem social autonomy family, school and general. The results of our social validation corroborate this explanation, as evidenced by participants who expressed the desire for a longer Taekwondo MTP intervention program. In our study, TKD group psychological development was observed(Table 1). The program was based on poomsaes that include physical movements as well as theoretical and philosophical principles. In addition, this traditional training approach that we adopted had intellectual components that could lead to the development of SEI. Moral development also improved in TKD group This result of our study is in agreement with the study of in which he conducted interviews with parents of martial artists. The parents said that their children have improved moral standards because of the practice of Taekwondo MTP intervention program. In this study, we had a similar result, of Funakoshi Taekwondo-based pedagogy. The participants in our study learned the principles of Taekwondo, mainly those developed by and links were explained on how to use and integrate some of them into real life situations beyond of our Taekwondo MTP intervention program. The data received indicate that they found a positive experience positive after Taekwondo MTP intervention program. The parents of the TKD group emphasized the moral and constructive impact of this Taekwondo MTP intervention program in the daily lives of these adolescents with ADHD. Compared to our study, others reported similar results from martial arts intervention studies on SEI in different population groups. Also the findings of Schmidt (1988), is in agreement with our study who found significant improvement in SEI through martial arts training for periods of eight to twenty-four weeks. According to our results Taekwondo MTP intervention program had an improvement of SEI in adolescents with ADHD. 


\section{Conclusion}

Taekwondo can be a good form of psychological, mental sensibilities and have progressive character- regard after a training session for adolescents with ADHD who train in the MTP intervention program. Taekwondo MTP intervention program can improve both better bodies and better minds among adolescents with ADHD and may lead to a better, more peaceful society. Possibly the positive results shouldn't come as a surprise. It's gratifying to know that probe is beginning to support the claims of the others studies. Therefore, Taekwondo could be considered as a becoming non-pharmacological restorative tactics for the substances with ADHD from a adolescent age. Despite the answered questions about how these changes do among adolescents with ADHD, the martial handicrafts are chancing a niche in the treatment of internal illnesses and will likely prove to be a useful complement [32]. 


\section{References}

1. Harter S (1988) The Self-Perception Profile for Adolescents. Denver, CO.

2. Harter S (1990) Causes, correlates, and the functional role of global self-worth: A life-span perspective.

3. Harter S (1997) The development of self-representation. Dans W.D Eisenberg (Eds.), Handbook of child psychology: Vol. 3. Social, emotional and personality development (pp. 553-618). New York: Wiley.

4. Van Andel GE and Austin DR (1984) Physical Fitness and Mental Health: A Review of the Literature. Adapted Physical Activity Quarterly 1: 207-20

5. Weiser M, Kutz I, Kutz SJ and Weiser D (1995) Psychotherapeutic Aspects of the Martial Arts. Am J Psychotherapy 49: 118-27.

6. Guthrie SR (1997) Defending the Self- Martial Arts and Women's Self Esteem. Women in Sport and Physical Activity J 6: 1-28.

7. Yang DY (1997) The Effects of Martial Arts Education and Self-Esteem Enhancement Program on the Construct of Children's Self-Esteem. Doctor of Philosophy, Howard University, Washington, D.C.

8. Weinberg RS, Daniel Gould D (1999) Foundations of Sport and Exercise Psychology

(2nd ed.). Champaign, IL: Human Kinetics.

9. Vealey RS (1986) Conceptualization of sport-confidence and competitive orientation: preliminary investigation and instrument development. J Sport Psychol 8: 221-46.

10. Richman CL, Rehberg H (1986) The development of self-esteem through the martial arts. Int J Sport Psychol 17: $234-9$.

11. Hogan J (2006) Taekwondo Patterns, From Beginner to Black Belt. United Kingdom: The Crowood Press.

12. Anthony MO (2005) The Use of Basic Karate Techniques to Enhance Self-Efficacy. Doctor of Philosophy, Northcentral University, Prescott, Arizona.

13. Suler JR (1993) Contemporary Psychoanalysis and Eastern Thought. State University of New York Press: Albany. pp. 163-240.

14. Seitz FC, Olson GD, Locke B and Quam R (1990) The Martial Arts and Mental Health: The Challenge of Managing Energy. Perceptual and Motor Skills 70: 459-64.

15. Saposnek DT (1980) Aikido: A Model for Brief Strategic Therapy. Family Process 19: 227-38.

16. Coppersmith S (1984) Manual of the self-esteem inventory of Coopersmith S. Paris: editions of the center of applied psychology; SEI, French translation.

17. Cohen J (1988) Statistical power analysis for the behavioral sciences. Hillside. NJ: Lawrence Earlbaum Associates.

18. Caldwell K, Harrison M, Adams M, Triplett TN (2009) Effects of Pilates and taiji quan training on self-efficacy, sleep quality, mood, and physical performance of college students. J Bodywork and Movement Therapies 13: 155-63. 
19. Dechamps A, Onifade C, Decamps A, Bourdel-Marchasson I (2009) Health-Related Quality of Life in Frail Institutionalized Elderly: Effects of a Cognition-Action Intervention and Tai Chi. J Aging and Physical Activity, 17: 236-48.

20. Marsh HW, Richards GE, Johnson S, Roche L, Tremayne P (1994) Physical Self-Description Questionnaire: Psychometric properties and the multitrait-multidimethod analysis of relations to existing instruments. J Sport \& Exercise Psychol 16: 207-305.

21. Li F, Harmet P, Chaumeton NR, Duncan TE, Dincan SC (2002) Tai Chi as a Means to Enhance Self-Esteem: A Randomized Controlled Trial. J Appl Gerontol 21: 70-89.

22. Lee LY, Lee DT, Woo J (2010) The psychosocial effect of Tai Chi on nursing home residents. Journal of Clinical Nursing 19: 927-38.

23. Jones GW, Mackay KS, Peters DM (2006) Participation Motivation in Martial Artists in the West Midlands Region of England. J Sports Sci and Medi Combat Sports Special Issue 28-34.

24. Winkle JM, Ozmun JC (2001) Teaching Martial Arts for Fitness and Fun: A Noncontact Approach for Young People: Human Kinetics.

25. Wong SE (2010) Single- Case Evaluation Designs for Practitioners. J Social Service Res 36: 248-59.

26. Finkenberg M (1990) Effect of participation in taekwondo on college women's self-concept. Perceptual and Motor Skills 71: $891-94$.

27. Funakoshi G, Nakasone G (2003) The Twenty Guiding Principles of KARATE (J. Teramoto, Trans. Bilingual edition ed.): Kodansha International.

28. Ryan MP (2008) The antidepressant effects of physical activity: Mediating self-esteem and self-efficacy mechanisms. Psychol and Health 23: 279-307.

29. Lantz J (2002) Family Development and The Martial Arts: A phenomenological Study. Contemporary Family Therapy 24: 565-80.

30. Anthony MO (2005) The Use Basic Karate Techniques to Enhance Self-Efficacy. Doctor of Philosophy, Northcentral University, Prescott, Arizona.

31. Lakes K, Hoyt W (2004) Promoting self-regulation through school- based martial arts training. Appl Developmental Psychol 25: 283-302.

32. Schmidt RJ (1988) The Effects of Shotokan Karate Training on Self Concept and Eatern Cultural Value Orientation of College Men and Women. Doctor of Philosophy, the University of Nebraska, Lincoln, Nebraska 